\title{
A PROTEÇÃo DO CONSUMIDOR PELO DIREITO INTERNACIONAL privado do Mercosul e da União Européia \\ BREVES OBSERVAÇÕES h̀s VÉSPERAS DAS NEGOCIAÇÕES DE UMA \\ Convenção In'teramericana de Direíto \\ Internacional Privado
}

\section{Thomas Richter ${ }^{1}$}

\section{IN'TRODUÇÃO}

O debate sobre a proteção do consumidor é de extrema atualidade e ultrapassa as fronteiras nacionais para internacionalizar-se. Mas não somente o debate se intemacionaliza; sobretudo as relações consumeristas se "internacionalizam" cada vez mais e demandam soluções não somente de normas materiais como também de direito internacional privado, a través de jogo de normas de conflitos de lei e de conflitos de jurisdição. Nessa busca de soluções no âmbito do direito internacional privado, tanto as iniciativas legislativas nacionais, quanto as intemacionais e as supranacionais merecem destaque. $O$ tratamento do tema adquire especial relevância em razão das negociações atuais no âmbito da Organização dos Estados Americanos, em tomo de uma Convenção Interamericana sobre a lei a alguns contratos de consumo.

Este artigo pretende, assim, tratar da proteção do consumidor pelo direito intemacional privado do Mercosul e da União Européia, abordando as questões de competência jurisdicional (I) e da lei aplicável (I). Para ilustrar a problemática, tomaremos un caso fictício com duas variantes, $A$ e B:

Caso celular A. Um turista brasileiro adquire na Argentina um telefone celular destinado ao uso privado. De volta ao Brasil, o turista descobre que o aparelho tem um defeito. $\mathrm{O}$ comprador brasileiro solicita para o vendedor a troca do telefone ou o reembolso do valor pago, mas em vão. Em face dessa situação, o comprador brasileiro decide ingressar com uma ação judicial contra o vendedor, pela ocorrência de vício do produto.

Caso celular B: O turista não sai do scu domicílio e compra o telefone celular em um site de vendas na internet, mantido pelo vendedor argentino.

\footnotetext{
Doutor em Direito pela Univetsidalte de Constinça (Alemanha). Bolsista de Pós-Doutorado do Serviço Alemão de Intercâníio Acadênico (Deutscher Akadernischer Austanchdienst -... DAAD). Professor convidudo da Faculdade de Direito da, Universidade Federal to Rio Grancle do Sul. Contato: thomas-m-richter@web.de.
} 
Estas duas hipóteses de trabalho serão confrontadas às soluções oferecidas por cada sistema jutídico ao final da exposição de cada um deles. Quanto ao direito do Mercosul e da União Européia, referimo-nos exclusivamente à notmativa stricto sensu de ambas Organizações, excluindo as soluções nacionais, oferecidas pelo direito intemacional privado de cada um dos Estados-Membros.

\section{COMPETÊNCIA INTERNACIONAL}

Entende-se como competência internacional a vocação dos tribunais de um Estado, considerados no seu conjunto, de conhecer e julgar um litígio que apresenta conexão com mats de um ordenamento jurídico.

Antes de verificarmos o atual tratamento da matéria na União Européia (B), tomaremos conhecimento das normas que a disciplinam no âmbito do Mercosul (A).

\section{A. Direito do Mercosul}

No âmbito do Mercosul, dois são os instrumentos destinados ao enfrentamento da questão. De um lado, temos o Protocolo de Buenos Aires de 1994 sobre a jurisdição internacional em matéria contratual (1), de outro lado, temos o Protocolo de Santa Maria de 1996 sobre jurisdição intemacional em matéria de relações de consumo (2). Após conhecermos estes dois instrumentos, verificaremos as soluções que eles oferecem às hípóteses de trabalho sugeridas na introdução (3).

\section{Protocolo de Buenos Aires de 1994}

O Protocolo de Buenos Aires ${ }^{2}$ permite a eleição de foro entre as partes contratantes (Art 4-6). $O$ art. 7 determina que "en ausencia de acuerdo tienen jurisdicción, a elección del actor, los jueces del lugar de cumplimiento del contrato, los jueces del domicilio del demandado o los jueces de su domicilio o sede social cuando demostrare que cumplió con su prestación".

No que diz respeito aos contratos conclúdos por um consumidor, o Protocolo de Buenos Aires limita o seu campo de aplicação, embora pareça não os excluir de tudo. Nos termos do Art. 2, al. 6, ficam exclú́dos do seu campo de aplicação somente os contratos de compra e venda, in uerbis.

"Art. 2. O âmbito de aplicação do presente Ptotocolo exclui:

$[\ldots]$

6. os contratos de venda ao consumidor,"

2 Protocolo de Buenos Aires sobre Junisdicción Intemacional en Materia Contractual de 5 de agosto de 1994, MERCOSUR/ CMC/Dec. No 1/94, publicado em http:/ www.mercosurint/msweb/pagi na_anterior/samlesparol/snor/normativa/

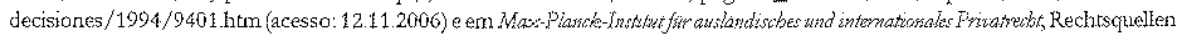
des MERCOSUR, Teilband 1, p. 230 . 
Em matéria de venda intemacional, parece que o legislador do Mercosul estimou que os contratos concluídos por consumidores mereciam um tratamento especial, a ser realizado por meio de um Protocolo particular. Deixou-o, no entanto, em aberto a questão de saber se - Protocolo de Buenos Aires se aplica a outros tipos de contratos concluídos por um consumidor, tais como os de serviço ou de locação...

\section{Protocolo de Santa Maria de 1996}

Em razão do linite estabelecido no Protocolo de Buenos Aires, foi aprovado o Protocolo de Santa Maria de $1996^{3}$, que regula a jurisdição intemacional em matéria de relações de consumo.

A tegra geral encontra-se no art. 4 , que dita:

"1. Terão jurisdição intemacional nas demandas ajuizadas pelo consumidor, que versem sobre relações de consumo, os juízes ou tribunais do Estado em cujo território esteja domiciliado o consumidor.

2. O fornecedor de bens ou serviços poderá demandar contra o consumidor perante o juiz ou tribunal do domicílio deste."

Algumas soluções alternativas também são previstas pelo Protocolo, que em seu art. $5^{\circ}$ dita:

"Também terá jurisdição internacional, excepcionalmente e por vontade exclusiva do consumidor, manifestada expressamente no momento de ajuizar a demanda, o Estado:

a) de celebração do contrato;

b) de cumprimento da prestação de serviço ou da entrega dos bens,

c) de domicilio do demandado."

Por fim, se o demandado tiver domićlio em um Estado Parte e em outro Estado Parte, filial, sucursal, agência ou qualquer outra espécie de representação com a qual redìzou as operações que geraram o conflito, o consumidor poderá demandar em qualquer dos referidos Estados (art. 6).

Protocolo de Santa Maria até agora não entrou em vigor. Está vinculado, pelo seu artigo 18, à aprovação do "Regulamento Comum MERCOSUL de Defesa do Consumidor" em sua totalidade, inclusive eventuais anexos, pelo Conselho do Mexcado Comum.

Sendo o Protocolo de Santa Maria inaplicável, reforça-se a exclusão dos contratos de venda ao consumidor pelo art. 2, n. $^{\circ} 6$ do Protocolo de Buenos Aires. Todavia, ressurge a

\footnotetext{
Protocolo de Santa Maria sobre Jurisdição Internacional em Matéria de Relaçôes de Consuno, de 22 de novembro de 1996 , MERCOSUL/CMC/Dec. No 10/16, Boletim de Integraçấ Latino-Amexcanat no 19 (1996), p. 52 e http://www.ruercosur.int/ msweb/principal/conterido.asp (acesso: 12.11.2006).
} 
questão de saber se essa exclusão deveria ser alargada para todos os contratos com consumidores ${ }^{4}$, como contratos de aluguel ou contratos de prestação de uma obra (como reparação de carro, denominados, em alemão, de Werkevertraege), ou não.

\section{Hipótese de trabalho: o caso do aparelho celular}

Caso A: O Protocolo de Buenos Aires não é, aplicável, pois se trata de um contrato de venda ao consumidor (Art. 2 , n. ${ }^{\circ} 6$ do Protocolo de Buenos Aires). O Protocolo de Santa Maria não está vigente. A competência internacional é regida, então, pelo direito processual civil do foro. Se fosse aplicável o Protocolo de Santa Maria, o comprador brasileiro poderia ingressar com uma ação perante os tribunais brasileiros (Art. 4, parágrafo 1 do Protocolo).

Caso $B: O$ resultado é o mesmo.

\section{B. União Européia}

Antes de apresentarmos as regras européias relativas à competência intemacional dos tribunais dos Estados-Membros da União Européia (2), conheceremos brevemente o instrumento que as instituiu (1). Após confrontarmos suas soluções à nossa hipótese de trabalho (3).

\section{O Regulamento $44 / 2001$}

a) Sucedáneo da Convenção de Bruxelas

O Regulamento $44 / 2001^{5}$, chamado "Regulamento Bruxelas I", é sucedâneo da Convenção de Bruxelas de 1968. Essa última foi instituída entre Estados membros da CE como resultado da aplicação do antigo art. 220 do Tratado de Roma (art. 293 do TCE).

Art. $2933^{\circ}$ TCE diz:

"Os Estados-Membros entabularão entre si, sempre que necessário, negociações destinadas a garantir, em beneficio dos seus nacionais:

$[\cdots]$

- a simplificação das formalidades a que se encontram subordinados o reconhecimento e a execução recíprocos tanto das decisões judiciais como das decisões arbitrais."

Em 1971, os Estados contratantes estabeleceram o Protocolo de Luxemburgo, relativo à interpretação da Convenção pelo Tribunal Europeu de Justiça.?

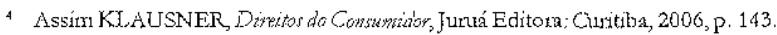

SRegulamento (CE) N. 44/2001 do Conselho, de 22 de Dezembro de 2000 , relativo à competencia juciciánin, ao reconhecimento

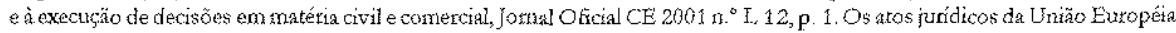
são acessiveis sob hitţ: / / urwentropacuint/eur-lex (acesso: 12.11.2006).

- Convenção relativa à competência judiciátia è execuçäo de decisôes em matéria civil e comercial, Jo mal O ficial CE $1998 \mathrm{n}{ }^{\circ}$ C 27, p. 3

7 Protocolo relativo à intexpretação pelo Tribunal de fustiga da Convenção de 27 de Setembto de 1968, relatjviz à competência judiciána e ì execução de decisóes em matéria civil e conercial, Joral Oficial CE 1998 n $^{\circ} \mathrm{C} 27$, p. 28 
Como os membros da European Free Trade Association (EFTA) ${ }^{8}$ quiseram participar nos efeitos da Convenção de Bruxelas, mas sem sumeter-se à jurisdição do Tribunal Europeu de Justiça, foi instituída entre eles e os Estados-membros da CE a Convenção de Lugano de $1988^{\circ}$. Por essa razão, a Convenção de Lugano tem como base a Convenção de Bruxelas, com poucas modificações.

O Regulamento Bruxelas I é o resultado de uma modemização da Convenção de Bruxelas. A alteração mais debatida foi a ampliação do campo de aplicação em casos de contratos de consumo.

O Regulamento lida, como as Convenções de Bruxelas e de Lugano, tanto com a competência intemacional (Art. $2^{\circ}-31$ ), quanto com o reconhecimento e a execução (Art. 3256). As normas de reconhecimento e de execução de decisões evidenciam uma confiança recíproca entre os Estados membros da União Européia, e foram completadas, em 2005, pelo Regulamento sobre o Título executivo europeu para créditos não contestados. ${ }^{10}$ Este revoga, dentro do seu âmbito de aplicação, o exequatur. No entanto, o tema da assistência judicial ficará fora desse artigo, com vistas a não desequilibrar o quadro comparativo.

\section{b) Base juridica do Regulamento}

A União Européia é uma entitade supranacional. Por meio do Tratado que institui a Comunidade Européia (TCE) ${ }^{1 !}$, os Estados-Membros transmitiram parte de sua soberania à Comunidade. O Regulamento europeu por sua vez é uma lei européia que tem efeito direto e imediato, e vige en toda o território da União Européia, sem que para isso seja necessária sua incorporação pelos Estados-Membros.

Art. 249, parágrafo 2 TCE diz:

"O regulamento tem carácter geral. É obrigatório em todos os seus elementos e directamente aplicável en todos os Estados-Membros."

A base jurídica para atos europeus de direito intemacional privado foi estabelecida pelo Título IV do Tratado de Amsterdam de $1997^{12}$, que introduziu no TCE uma competência comunitária sobre o assunto:

Art. 61 alínea c) TCE diz:

"A fim de criar progressivamente um espaço de liberdade, de segurança e de justiça, o Conselho adoptará medidas no domínio da cooperação judiciária em matéria civil, previstas no artigo $65^{\circ}$ "'

(2) Vejahtp: / whwwefta int (acesso: 12.11.2006)

- Convenção relativa à competência judiciátia e ì execuçäo de decisöes mm matéria civil e comercial, celebrada em Lugano, em 16 de setembro de 1988 ( $88 / 592 / \mathrm{CEE}$ ), Jomal Ofrial CE $1988 \mathrm{n}^{\circ} \mathrm{L} 319$, p. 9

$\checkmark$ Regularmento (CE) n" 805/2004 do Parlamento Europeu e do Conselho, de 21 de Abril de 2004, que cria o titulo executivo europeu para créditos näo contestados, Jomal Oficial CE $2004 n^{\circ}$ I. 143, p. 15, aplicável desde 21 de outubro de 2005. 
Art. 65 TCE diz:

"As medidas no domínio da cooperação judiciária em matéria civil que tenham uma incidêtncia transfronteiriça, a adoptar nos temos do artigo $67 .^{\circ}$ e na medida do necessário ao bom funcionamento do mercado inteno, terão por objectivo, nomeadamente

a) Melhorar e simplificar:

$-[\ldots]$

- o reconhecimento e a execução das decisões em matéria civil e comercial, incluindo as decisões extrajudiciais;

b) Promover a compatibilidade das nomas aplicáveis nos Estados-Membros em matéria de conflitos de leis e de jurisdição.

c) $[\ldots]^{\prime \prime}$

Os instrumentos europeus de direito internacional privado serão vigentes no Reino Unido e na Itlanda, somente quando esses países declararem participar na aprovação e aplicação desses instrumentos. ${ }^{13}$ Nenhum instrumento europeu de direito intemacional privado é vigente na Dinamarca, pelo fato desse país não ter ratificado o Título IV do 'Tratado de Amsterdam de $1997^{14}$. Dessa situação especial decorre a manutenção ainda vigor da Convenção de Bruxelas quanto à competência internacional dos tribunais dinamarqueses.

\section{Competência internacional}

a) Regrageral

A regra geral de competência intemacional estabelecida no Art. $2^{\circ}$ protege o requerido:

"Artigo 2."

1. Sem prejuizo do disposto no presente regulamento, as pessoas domiciliadas no rerritório de um Eistado-Membro devem ser demandadas, independentemente da sua nacionalidade, perante os tribunais desse Estado.

2. As pessoas que não possuam a nacionalidade do Estado-Membro em que estão domiciliadas ficam sujeitas nesse Estado-Membro às regras de competência aplicáveis aos nacionais."

11 Tratado que instani a Comunidade Européta, versăo do Tratado de Anzterda, Jomal Ofical CE $2002 \mathrm{n}^{\circ} \mathrm{C} 325$, p. 33 .

¿ Trarado de Amsterdan de 17 de junho de 1997, Joma Oticial CE $1997 \mathrm{n}^{\circ} \mathrm{C} 340$, p 1 , em vigor desce $1^{\circ}$ de maio de 1999.

- Protocolo $n^{\circ} 4$ sobre a posição do Reino Uñdo e da Irlanda, anexo ao Tratado que institui a Comunitade Européia, Jomal Oticial $1997 \mathrm{n}^{\circ} \mathrm{C} 340, \mathrm{p} 173$.

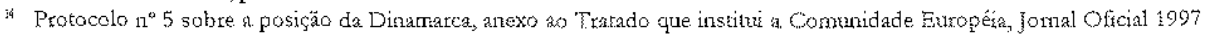
I. C $340,0.173$. 


\section{b) Competências especiais}

A seção 2 (Artigos 5-7) do Regulamento Bruxelas I lida com as competências especiais, que são independentes do campo pessoal de aplicação, ou seja, das pessoas envolvidas.

Quanto ao direito contratual, a norma mais importante é Art. $5 \mathrm{n}^{\circ} 1$ :

"Artigo 5."

Uma pessoa com domicilio no território de um Estado-Membro pode ser demandada noutro Estado-Membro:

1. a) Em matéria contratual, perante o tribunal do lugar onde foi ou deva ser cumprida a obrigação em questão;

b) Para efeitos da presente disposição e salvo convenção em contrário, o lugar de cumprimento da obrigação em questão será:

- no caso da venda de bens, o lugar num Estado-Membro onde, nos termos do contrato, os bens foram ou devam ser entregues,

- no caso da prestação de serviços, o lugar num Estado-Membro onde, nos termos do contrato, os serviços foram ou devam ser prestados;

c) Se não se aplicar a alínea b, seráa aplicável a alínea a."

c) Competência especial para contratos celebrados por consumidores

Em matéria de contratos concluídos pelos consumidores, o Regulamento prevê regras derrogatórias do regime geral previsto no art. 2 , bem como daquelas relativas às competências especiais previstas na seção 2 . Téndo $\mathrm{cm}$ vista seu caráter auto explicativo, permitimos a reprodução dos dispositivos concernente os contratos celebrados por consumidores no âmbito do território da União Européia. Tais regras estão inscritas na seção 4 do regulamento e dizem respeito ao seu campo de aplicação (art. 15), à regra de competência intemacional (art. 16) e à eleição de foro sob certas condições (art. 17).

"Secçã̃ 4

Competência em matéria de contratos celebrados por consumidores Atrigo 15

1. Em matéria de contrato celebrado por uma pessoa para finalidade que possa ser considerada estranha à sua actividade cometcial ou profissional, a seguir denominada "o consumidor", a competência será determinada pela presente secção, sem prejuízo do disposto no artigo 4.0 e no ponto 5 do artigo $5^{\circ}$ :

a) Quando se trate de venda, a prestações, de bens móveis corpóreos; ou

b) Quando se trate de empréstimo a prestações ou de outra operação de crédito relacionados com o financiamento da venda de tais bens; ou 
c) Em todos os outros casos, quando o contrato tenha sido concluído com uma pessoa que tem actividade comercial ou profissional no Estado-Membro do domicílio do consumidor ou dirige essa actividade, por quaisquer meios, a esse Estado-Membro ou a vários Estados incluindo esse Estado-Membro, e o dito contrato seja abrangido por essa actividade.

2. O co-contratante do consumidor que, não tendo domicílio no território de um Estado-Membro, possua sucursal, agência ou qualquer outro estabelecimento num EstadoMembro será considexado, quanto aos litígios relativos à exploxação daqueles, como tendo domićlio no território desse Estado.

3. O disposto na presente secção não se aplica ao contrato de transporte, com excepção do contrato de fornecimento de uma combinação de viagem e alojamento por um preço global.

\section{Artigo 16}

1. O consumidor pode intentar uma acção contra a outra parte no contrato, quer perante os tribunais do Estado-Membro em cujo território estiver domiciliada essa parte, quer perante o tribunal do lugar onde o consumidor tiver domicílio.

2. A outra parte no contrato só pode intentar uma acção contra o consumidor perante os tribunais do Estado-Membro en cujo território es tiver domiciliado o consumidor.

3. O disposto no presente artigo não prejudica o direito de formular um pedido reconvencional perante o tribunal em que tiver sido instaurada a acção principal, nos termos da presente secção.

\section{Artigo 17}

As partes só podem convencionar derrogações ao disposto na presente secção desde que tais convenções:

1. Sejam posteriores ao nascimento do litígio; ou

2. Permitam ao consumidor recorrer a tribunas que não sejam os indicados na presente secção; ou

3. Sejam concluídas entre o consumidor e o seu co-contratante, ambos com domicílio ou residência habitual, no momento da celebração do contrato, num mesmo Estado-Membro, e atribuam competência aos tribunais desse Estado-Membro, salvo se a lei desse EstadoMembro não permitir tais convenções."

\section{O caso do aparelho celular}

Caso A: Aplicando os critérios de determinação da competência estabelecidos pelo Regulamento 44/2001 (Suposta aplicação territorial do Regulamento), o seu campo de aplicação não seria aberto. No caso $\mathrm{A}$, não são constatadas atividades comerciais ou profissionais no Brasil, da parte do vendedor, nem a direção de tais ațividades para o Brasil 
(art. 15, parágrafo 1, alínea $c$, do Regulamento Bruxelas 1). A competencia intemacional seria então regida pelo direito processual civil do foro.

Caso B: A utilização do site de vendas pela internet com a possibilidade de o comprador brasileiro contratar será considerada como direção de atividade para o Brasil (art. 15, parágrafo 1, alínea c do Regulamento "Bruxelas I"). O comprador é brasileiro, o celular está scndo destinado ao uso privado, logo o comprador brasileiro é consumidor (art. 15, parágrafo 1, alínea c do Regulamento "Bruxelas I"). Suposta a aplicação territorial do Regulamento "Bruxelas l", os tribunais brasileiros adquirem competência internacional (art 16 do Regulamento Bmxelas I).

\section{LEI APLICÁVEL}

Entende-se como lex aplicável a vocação das leis materiais de um Estado, consideradas no seu conjunto, de regular um litígio que aptesenta conexão com mais de um ordenamento juridico.

\section{A. Mercosul}

Em matéria de lei aplicável, o Mercosul é decididamente menos inovador que em matéria de conflito de jurisdição (1), o que leva a soluçôes baseadas no direito intemacional privado de cada Estado-Parte (2).

\section{Direito do Mercosul}

O Mercosul ainda não conhece nenhum instrumento determinando a lei aplicável em relação a contratos de consumo. Dois instrumentos somente parecem dizer respeito à lei aplicável: o primeiro, é o Protocolo de San Luis sobre a lei aplicável em matéria de responsabilidade civil derivada de acidentes de trânsito ${ }^{15}$; o segundo, é o Acordo sobre Arbitragem Comercial Intemacional, subscrito em Buenos Aites, em 23 de Jullio de 1998 (Decisão $\mathrm{n}^{\circ} 3 / 98$ do $\left.\mathrm{CMC}\right)^{16}$, que trata exclusivamente da arbitragem internacional entre particulares e permite que as partes elejam o direito aplicável à solução de controvérsias com base no direito internacional privado e seus princípios, assim como no direito do comércio internacional, devendo órbitro, caso as partes silenciem-se sobre a matéria, decidir conforme as mesmas fontes (art. 10).

\footnotetext{
1 Protocolo de San Luis em Matéria de Responsalilidad Crvil Ennergente de Accidentes de Tránsito, MERCOSUR/CMC/DeC. $N^{\circ} 1 / 96$, em vigor entre Paraguai e Urupuai, desde o dia 19 de agosto de 1999.

* Promulgado pelo Decreto ${ }^{\circ} 4.719$, ce 04 de maio de 2003,0 contétido deste Acordo é idêntico ao Acordo sobre a Arbitragern Conercial Intenacional furnado entre o Mercosul, a Repúulica da Bolíviz e República do Chíle (Decisão 1 ${ }^{\circ} 4 / 98$, do CMC). Para melhor compreensão destes e outros $A$ cordos sobte arbituagem intenacional ver NOODT TAQUELA, Arbitraje intmacional en el Mercosur, Buenos Aires: Ciudad Argentina, 1999
} 


\section{O caso do aparelho celular}

Supondo que o tribunal competente seja o brasileiro e que, por conseqüêtncia o juiz brasileiro aplique a regra de conflito brasileira (do foro), as soluçôes às nossas hipóteses de trabalho apresentarão as seguintes configurações:

Caso A: Segundo o art. $9^{\circ}$, caput da LICC, aplica-se a lei do pax́s em que a obrigação se constituiu. $O$ contrato foi celcbrado na Argentina. Será aplicável a lei argentina.

Caso B: "Tratando-se de uma contratação entre ausentes, aplica-se o $\$ 2^{\circ}$ do artigo $9 \mathrm{da}$ LICC. ${ }^{17}$ Neste caso, será igualmente competente a lei brasileira, porque a residência do proponente (consumidor brasileiro) é no Brasil e, segundo aquele dispositivo, a obrigação resultarate do contrato reputa-se constituída no lugar em que residir o proponente. ${ }^{18}$

\section{B. União Européia}

Assim como em matéria de competência internacional, a União Européia possui uma convenção sobre a lei aplicável aos contratos intemacionais: a Convenção de Roma de 1980 (1). Tal como a Convenção de Bruxelas de 1968, a Convenção de Roma deve em breve transformar-se em um Regulamento europeu (2). Após a apresentação da Convenção e da proposta da Comissão européia, restar-nos-á confrontar suas soluções com as hipóteses formuladas na introdução (3).

\section{Convenção de Roma de 1980}

Desde 1980 , o direito intetnacional privado europeu aplicável aos contratos intemacionais encontra-se formulado na Convenção de Roma de 1980 sobre a lei aplicável às obrigações contratuais ${ }^{19}$. As regras de conflito aplicável às relações de consumo está inscrita no art. $5 \mathrm{da}$ Convenção, que dita:

"Artigo 5". Contratos celebrados por consumidores.

1. O presente artigo aplica-se aos contratos que tenham por objecto o fornecimento de bens móvets corpóreos ou de serviços a uma pessoa, o «consumidon, para uma finalidade que pode considerar-se estranha à sua actividade profissional, bem como aos contratos destinados ao financiamento desse fornecimento.

2. Sem prejuizo do disposto no artigo $3^{\circ}$, a escolha pelas partes da lei aplicável não pode ter como conseqüência privar o consumidor privado da proteç̧ão que the garantem as disposições imperativas da lei do país em que tenha a sua residência habitual:

- se a celebração do contrato tiver sido precedida nesse pais, de uma proposta que the foi especialmente dirigida ou de anúncio publicitário, e se o consumidor tiver executado nesse pás todos os actos necessários à celebração do contrato, ou

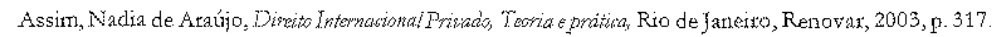

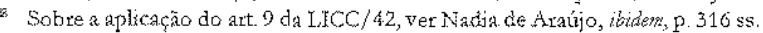

D Convenç̃̃o de Roma de 19 de junho de 1980 (80/934/CEE), Jo mal Ofrcial CE 1980 n 266 , p. 1.
} 
- se a outra parte ou o respectivo representante tiver recebido o pedido do consumidor nesse país, ou

- se o contrato consistir numa venda de mercadorias e o consumidor: se tenha deslocado desse país a um outro país e á tenha feito o pedido, desde que a viagem tenha sido organizada pelo vendedor com o objectivo de incitar o consumidor a comprar.

3. Sem prejuízo do disposto no artigo $4^{\circ}$ e na falta de escolha feita nos termos do artigo $3^{\circ}$, esses contratos serão regulados pela lei do país em que o consumidor tiver a sua residência habitual, se se vetificarem as circunstâncias referidas no $\mathrm{n}^{\circ} 2$ do presente artigo.

4. O presente artigo não se aplica:

a) Ao contrato de transporte;

b) Ao contrato de prestação de serviços quando os serviços devidos ao consumidor devam ser prestados exclusivamente num país diferente daquele em que este tem a sua residência habitual.

5. Sem prejuízo do disposto no $\mathrm{n}^{\circ} 4$, o presente artigo aplicamse ao contrato que estabeleça, por um preço global, prestações combinadas de transporte e de alojamento."

Salienta-se que esta regra é especial e traz condições especiais ao exercício da liberdade que têm as partes de escolher a lei aplicável, segundo a regra geral estabelecida nos art. 3 , permitindo assim a aplicação repartida de leis distintas (dépefage).

\section{Projeto de Regulamento "Roma I"}

A Convenção de Roma está em processo de transformação em Regulamento Europeu. ${ }^{20} \mathrm{O}$ processo de transformação setá concluído, provavelmente, em $2008 .^{21}$

\section{a) Trabalbos preparatórios da Comissão Européia}

Em janeiro de 2002, a Comissão Européia publicou um Livto verde ${ }^{22}$, que tem como objetivo lançar uma ampla consulta dos metos interessados sobre um certo número de questões de ordem jurídica relativas à transformação da Convenção de Roma de 1980, sobre a lé aplicável às obrigações contratuais em um instrumento comunitário, bem como à eventual modemização dos seus aspectos essenciais.

Em fevereiro de 2005, a Comissão Européia abriu uma discussão dentro de um grupo de expertos, apresentando um anteprojeto de Regulamento, na forma de Discussion Paper. ${ }^{23}$

x) Proposta da Comissâo Européra de 15 de dezembro de 2005, COM (2005) 650 tinnal.

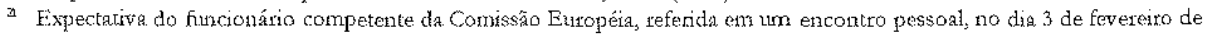
2006.

2. Liv to verde relativo à trans fomaçăo da Convenção ce Roma de 1980 , sobre a lei aplicível às obrigações contratuais em um ins linnento comunitário e sua modernizaçäo, CON (2002) 654 final, do 141.2002

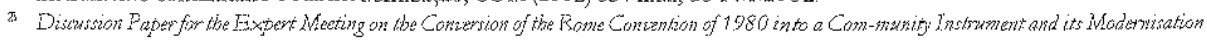
(Rome I"), (Bnixelas 17.2.2005, nầo publicado). 


\section{b) Proposta de Regulamento Roma I da Comissão Européia}

No dia 15 de dezembro de 2005, a Comissão Européia publicou uma proposta de sobre a lei aplicável às obrigações contratuais. ${ }^{24}$ Entre outras inovações, esta proposta contem uma nova versão do atual art. 5 da Convenção de Roma de 1980, que é distinta inclusive daquela primeiramente vislumbrada no Discussion Paper.

"Article 5-Contrats de consommation

1. Les contrats de consommation au sens et dans les conditions prévus au paragraphe suivant, sont régis par la loi de l'Etat membre dans lequel le consommateur a sa résidence habituelle.

2. Le paragraphe premier s'applique aux contrats conclus par une persome physique, le consommateur, qui a sa résidence habituelle dans un Etat membre, pour un usage pouvant être considéré comme étranger à son activité professionnelle, avec une autre personne, le professionnel, agissant dans l'exercice de son activité professionnelle. Il s'applique à condition que le contrat ait été conclu avec un professionnel qui exerce des activités commerciales ou professionnelles dans l'Etat membre de la résidence habituelle du consommateur ou qui, par tout moyen, dirige ces activités vers cet Etat membre ou vers plusieurs pays dont cet Etat membre, et que le contrat rentre dans le cadre de ces activités, à moins que le professionnel n'ignorait le lieu de la résidence habituelle du consommateur et que cette ignorance n'était pas imputable à une imprudence de sa part.

3. Le paragraphe premier ne s'applique pas aux contrats suivants:

(a) aux contrats de fourniture de services lorsque les services dus au consommateur doivent être fournis exclusivement dans un pays autre que celui dans lequel il a sa résidence habituelle;

(b) aux contrats de transport autres que les contrats portant sur un voyage à forfait au sens de la directive 90/314/CEE du 13 juin 1990;

(c) aux contrats ayant pour objet un droit réel immobilier ou un droit d'utilisation d'un immeuble autres que les contrats ayant pour objet un droit d'utilisation à temps partiel au sens de la directive 94/47/CE du 26 octobre 1994.

A grande inovação desta proposta em relação à Convenção de Roma está na substituição da autonomia da vontadade pela residência habitual do consumidor como critério de deterninação da lei aplicável aos contratos concluídos pelos consumidotes.

\section{O caso do aparelho celular}

Caso $A$ : O caso fica fora do campo de aplicação segundo o artigo $5 .^{\circ}$, parágrafo 2 da Convenção de Roma parágrafo. Também não entraria no campo de aplicação do Regulamento

* Comissĩo Européia, Proposta de Regulamento Roma I, de 15 de decemóro de 2005, COM (2005) 650, final. 
Roma I, na versão proposta pela Comissão Européia, pois não se constatam, da parte do vendedor, nenhuma atividade comercial ou profissional no território brasileiro, nem tampouco o direcionamento de tais atividades para o Brasil (Art. 5, parágrafo 2 da Proposta "Roma I"). A lei aplicável é regida pela regra de conflito do foro.

Caso B: Se levado em consideração o Regulamento Roma I na versão proposta pela Comissão Européia, o caso B encontrar-se-ia sob seu campo de aplicação. Com efeito, a utilização do site da intemet como meio de conclusão do contrato pelo comprador brasileiro será considerada como direcionamento de atividade cometcial ou profissional para o Brasil (art. 5, parágrafo 2 da Proposta "Roma I"). O comprador é brasileiro, o aparello celular está sendo destinado ao uso privado, logo o comprador brasileiro é consumidor (art. 5, parágrafo 1 da Proposta "Roma I").

\section{CONCLUSÃO: UMA CONVENÇÃO INTERAMERICANA}

A Organização dos Estados Americanos $(\mathrm{OEA})^{25}$ organiza regulamente Conferências Especializadas Interamericanas sobre Direito Internacional Privado (CIDIPs ${ }^{25}$ ). Estas são Conferências especializadias na elaboração de diversas convenções de direito intemacional privado, destinadas à adoção por todos os Estados membros da OEA.

A OEA conta atualmente com a participação de 35 Estados membros pertencentes às três Américas: Antigua and Barbuda, Argentina, The Bahamas, Barbados, Belize, Bolivia, Brasil, Canada, Chile, Colombia, Costa Rica, Cuba ${ }^{27}$, Dominica, República Dominicana, Ecuador, Ed Salvador, Grenada, Guatemala, Guyana, Haiti, Honduras, Jamaica, México, Nicaragua, Panamá, Paraguay, Peru, Saind Kitts and Nevis, Saint Lucia, Saint Vincent and the Grenadines, Suriname, Trinidad and Tobago, United States of America, Uruguay, Venezuela.

As CIDIPs são tealizadas pelo Departamento de Assuntos Jurídicos Internacionais da OEA, que tem sua sede em Washington D.C. ${ }^{28}$ Até o presente, foram realizadas as seguintes CIDIPs: ${ }^{29}$

- CIDIP I de 1975 na Cidade de Panamá, Panamá

- CIDIP II de 1979 em Montevidéu, Uruguai

- CIDIP III de 1984 em La Paz, Bolívia

- CIDIP IV de 1989 em Montevidéu, Uruguai

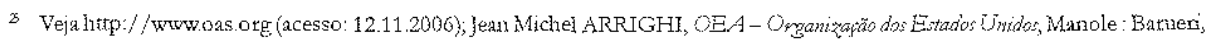
20033 .

× A abreviatura CIDIP utiliza-se também para "Convenção Interamericana sobre Direto Intemacional Privado".

v O governo cubano anzal to excluído da participaçáo, pela Resolução do 8. Retunão dos Misistros dos Reiações Extexiozes, em 1962.

3) Veja http://wwwoas.org/dil/esp/departamento_astuntos_juridicos_internacionales.htm (acesso: 12.11.2006).

DVejahttp://wwwoas.org/dil/esp/CIDIPI_homehtm (acesso: 12.11.2006) e páginas laterats desta. 
- CIDIP V de 1994 na Cidade de México, México

- CIDIP VI de 2002 em Washington, D.C., E.U.A.

A CIDIP V do México adotou uma "Convenção Interamericana sobre o Direito aplicável aos Contratos Internacionais". No entanto, essa convenção não contém nenhuma norma de proteção do consumidor e encontra-se em vigor somente entre o México e a Venezuela, que já a in ternalizaram.

A CIDIP VII foi convocada pela Assembléia Geral da OEA em 2003. Foram escolhidos dois temas: Proteção do consumidor e Garantias reais. Uma novidade da CIDIP VII é a discussão preparatótia na internet. ${ }^{30}$ A reunião preparałória de negociações será realizada em Porto Alegre, de $1^{\circ}$ até 4 de dezcmbro de 2006. Os maiores problemas a serem discutidos serão a inclusão de pessoas jurídicas na definç̧ão de consumidor, a regra de lei aplicável e a inclusão da competência internacional no texto da futura convenção.

O incremento das relações entre os países do Mercosul ģerou uma intemacionalização do debate em torno da proteçẫo dos consumidores situados nesse bloco económico. $A$ regulamentação dos direitos do consumidor no Mercosul tem-se mostrado, contudo, insuficiente.

Com vistas ao aperfeiçoamento do debate, é fundamental considerar a experiência desenvolvida pela Comunidade Européia, ainda que nem todos os institutos lá praticados sejam observados nas regras vigentes no Mercosul. Efetivamente, muito há que se fazer para que os direitos do consumidor sejam incrementados e desenvolvidos com finalidade de obtenção de uma proteção de caráter intemacional na América Latina. As CIDIPs são, nesse contexto, um importante espaço de reflexão sobre a necessidade de se promover a proteção do consumidor pelo direito internacional privado do Mercosul.

3 http:/ whwonsorg/dil/esp/derecho_intemacional_privado_foros.asp (acesso: 12.11.2006). 